\title{
Reactive compatibilization effect of graphene oxide reinforced butyl rubber nanocomposites
}

\author{
Sathishranganathan Chinnasamy ${ }^{1}$, Rajasekar Rathanasamy ${ }^{\text {* }}$ (D), Harikrishna Kumar Mohan Kumar ${ }^{1}$, \\ Prakash Maran Jeganathan ${ }^{2}$, Sathish Kumar Palaniappan ${ }^{3}$ and Samir Kumar Pal ${ }^{3}$ \\ ${ }^{1}$ Department of Mechanical Engineering, Kongu Engineering College, Tamil Nadu, India \\ ${ }^{2}$ Department of Food Science and Nutrition, Periyar University, Salem, Tamil Nadu, India \\ ${ }^{3}$ Department of Mining Engineering, Indian Institute of Technology, Kharagpur, West Bengal, India \\ *rajasekar.cr@gmail.com
}

\begin{abstract}
The objective of this work is to develop graphene oxide (GO) incorporated butyl rubber (IIR) nanocomposites by three different methods: direct addition approach (DAAM), single step method (SSM) and two step method (TSM). Chlorobutyl rubber was used as a compatibilizer in SSM and TSM. Mechanical properties of developed nanocomposites was increased and gas permeability co-efficient was decreased up on addition of GO content in IIR matrix. Maximum technical properties was achieved for the nanocomposite with $1.6 \mathrm{wt} . \%$ of GO in all methods was achieved due to better interfacial bonding with IIR matrix. When GO content increases above $1.6 \mathrm{wt} . \%$ in IIR matrix leads to agglomeration which resulted in deterioration of mechanical properties. HR-TEM studies revealed that nanocomposites prepared by TSM shows exfoliated structure of GO in IIR matrix due to homogenous distribution when compared to the nanocomposites prepared with DAAM and SSM.
\end{abstract}

Keywords: butyl rubber, graphene oxide, nanocomposite, mechanical.

How to cite: Chinnasamy, S., Rathanasamy, R., Kumar, H. K. M., Jeganathan, P. M., Palaniappan, S. K., \& Pal, S. K. (2020). Reactive compatibilization effect of graphene oxide reinforced butylrubber nanocomposites. Polimeros: Ciência e Tecnologia, 30(3), e2020032. https://doi.org/10.1590/0104-1428.05920

\section{Introduction}

Nanocomposites are currently used in several fields and new applications are being continuously developed like innerwalls of tires, thin film capacitors for computer chips, O-rings, ball bladders, fiber optic compounds, hand gloves, impellers blades and food packaging, etc ${ }^{[1]}$. Nanocomposites are materials which fused with nano-sized elements in the matrix to increase the macroscopic properties. The introduction of nanoscale, distribution of filler or measured nanostructures in the base matrix with high surface to volume ratio can enhance the physico-mechanical properties and unique functional behaviours of base material.

Rubber nanocomposites is one of the composites which were developed by several researchers around the world using different rubbers such as natural rubbe $\mathrm{r}(\mathrm{NR})^{[2-4]}$, butadiene rubber (BR), butyl rubber (IIR) ${ }^{[5]}$, chlorobutyl rubber $(\mathrm{CIIR})^{[6,7]}$, epoxidizednatural rubber $(\mathrm{ENR})^{[8]}$, styrene butadiene rubber (SBR), styrene butadiene styrene rubber (SBS) and nitrile butadiene rubber (NBR) for various applications. Even though IIR has its own merits and its property was enhanced with reinforcement of various nanosized fillers such as carbon black $(\mathrm{CB})^{[9]}$, silica, carbon nanotubes ${ }^{[10]}$, graphene $e^{[11,12]}$, graphene oxide $(\mathrm{GO})^{[13,14]}$ and nanoclay ${ }^{[15]}$. Amongst, GO is one of the filler utilized to improve the mechanical and gas barrier properties of IIR rubber compounds. This work aims to develop

IIR nanocomposites by reinforcing GO in presence and absence of compatibilizer using DAAM, SSM and TSM ${ }^{[16]}$. Mechanical and gas permeability properties of the prepared nanocomposites were evaluated and the properties of the nanocomposites was compared against the preparation method. CIIR was used as a compatibilizer in this work to achieve uniform dispersion of GO in the IIR matrix.

\section{Materials}

Butyl rubber and chlorobutyl with $1.25 \%$ of chlorine was purchased from Laxness and Bayer, Mumbai. Graphene oxide with a bulk density of $1.8 \mathrm{~g} / \mathrm{cm}^{3}$ and soluble in polar solvents was procured from Sigma Aldrich chemicals, Mumbai. Remaining chemicals like sulphur, zinc oxide, stearic acid ${ }^{[17]}, \mathrm{N}$-cyclohexyl-2-benzothiazyl sulphenamide (CBS) and tetramethylthiuram disulphide (TMTD) ${ }^{[18]}$ were obtained from Loba Chemicals, Chennai.

\section{Development of Composite}

Nanocomposite were prepared with and without compatibilizer $^{[19]}$. Nanocomposite without compatabilizer was developed by directly mixing of GO with rubber 
through DAAM. Nanocomposites with compatibilizer has been prepared by two approaches namely, SSM and TSM. CIIR ${ }^{[20-22]}$ was employed as a compatibilizer for both methods and the composition/ratio for the preparation of the composites was given in Table 1. In SSM, two roll mill was utilized to reinforce GO in IIR matrix in presence of compatibilizer. Curing and vulcanizing agents were also added along with rubber and GO in two roll mill.

Two roll mill was operated at atmospheric temperature and speed ratio of rotors was maintained at 1:14. Compression molding process was used for vulcanization and specimen preparation.

In TSM, Toluene ${ }^{[23]}$ was used as a solvent $(150 \mathrm{ml}$ for CIIR and $200 \mathrm{ml}$ for GO) to dissolve and disperse CIIR and GO separately in specific ratio $(1: 4 \mathrm{w} / \mathrm{w})$. Magnetic stirrer (800 rpm) was used to dissolve CIIR and GO separately until complete dissolution of CIIR and GO was attained. Dissolved CIIR solution was taken in the beaker, kept it in magnetic stirrer, dispersed GO was added directly in CIIR solution at the rate of $5 \mathrm{ml} / \mathrm{min}$ until GO solution was completely poured in CIIR solution and stirring process was continued till uniform mixture of CIIR and GO was obtained. Then, mixture was poured in glass plate and kept in plain surface at room temperature without any disturbance until film like material was obtained. Two roll mixing mill[24] was used to mix the acquired film, pure IIR and other ingredients (curing and vulcanizing agents) according to the ratio mentioned in Table 1. Resultant material was molded and vulcanized using compression moulding process.

\section{Characterization of Nanocomposites}

\subsection{Mechanical properties}

Mechanical properties of the samples were determined based on the ASTM D-412-06 standard using a universal tensile testing machine. Specimens for tensile and tear testswere obtained from the molded slabs ${ }^{[25]}$. Values oftensile strength, elongation at break and tear strength were recorded.

\subsection{Gas Permeability Co-efficient (GPC) measurement}

$\mathrm{GPC}^{[26-28]}$ of the developdcompositeswere studiedusing automated diffusion permeameter. Nitrogen gas (XL grade) was purchased to measure the gas permeability for prepared nanocomposites from BOC Gases, India. Nitrogen gas was passed at a constant pressure of 3.5 bar at $35^{\circ} \mathrm{C}$ for a time period of $30 \mathrm{~min}$ through the prepared nanocomposite. For isothermal measurement conditions the apparatus was placed in a thermostatically controlled environment.Time lag method is used to calculate gas barrier measurement. Mean permeability coefficient $(\mathrm{P})^{[5]}$ was determined with steady state gas pressure increment $(\mathrm{dp} / \mathrm{dt})$ in the calibrated volume $(\mathrm{V})$. The permeability coefficients were calculated from Equation 1

$$
\mathrm{P}=\frac{\mathrm{VdT}_{\mathrm{o}}}{\mathrm{Ap}_{\mathrm{i}} \mathrm{p}_{\mathrm{o}} \mathrm{T}}\left[\frac{\mathrm{dp}}{\mathrm{ds}}\right]_{\mathrm{S}}
$$

where, $\mathrm{P}, \mathrm{V}, \mathrm{d}, \mathrm{T}, \mathrm{A}, \mathrm{Po}, \mathrm{Pi}, \mathrm{T}$ and $\left.\mathrm{d}_{\mathrm{p}} / \mathrm{d}_{\mathrm{s}}\right)_{\mathrm{s}}$ denotes mean permeability coefficient, calibrated volume, thickness of the film, standard temperature, effective permeation area, standard pressure, upstream side of the film with a gas pressure of 3.5 bar, temperature of measurement and steady state gas pressure increment.

\subsection{High Resolution Transmission Electron Microscopy (HR-TEM)}

Morphology of the prepared composites was analyzed using HR-TEM (JEOL, USA). The thickness of the sample was maintained as $80 \mathrm{~nm}$ to record the images of the samples under HR-TEM ${ }^{[29]}$.

\section{Results and Discussion}

\subsection{Mechanical properties}

Mechanical property is one of the dynamic property of any composites for its applications. Hence, in this study, mechanical properties such as tensile strength (TS), tear strength (TES), percentage of elogantion(\% E) and modulus at 100 and $300 \%{ }^{[30]}$ were determined and outcomes were depicted in Figures 1-4. Mechanical properties of nanocomposites increases as weight content of $\mathrm{GO}$ increases in IIR matrix. Nanocomposites containing IIR with GO content of $1.6 \mathrm{wt} . \%$ (D4, S4 and T4) exhibited higher TS, TES and modulus at 100 and $300 \%$ when compared to pure IIR in all three preparation methods (DAAM, SSM and TSM). TS, TES and modulus at 100 and $300 \%$ decreases when GO content increases to $2 \mathrm{wt} . \%$ in IIR matrix. While

Table 1. Formulation of rubber nanocomposites.

\begin{tabular}{|c|c|c|c|c|c|c|c|c|c|c|c|c|c|c|c|c|}
\hline \multirow{4}{*}{ Components } & \multirow{4}{*}{$\mathbf{C N}$} & \multirow{2}{*}{\multicolumn{5}{|c|}{$\begin{array}{l}\text { IIR Nanocomposites(without } \\
\text { compatibilizer) }\end{array}$}} & \multicolumn{10}{|c|}{ IIR Nanocomposites(with compatibilizer) } \\
\hline & & & & & & & \multicolumn{5}{|c|}{ Single step mixing method } & \multicolumn{5}{|c|}{ Two step mixing method } \\
\hline & & \multicolumn{15}{|c|}{ parts per hundred rubber of weight (phr) } \\
\hline & & D1 & D2 & D3 & D4 & D5 & S1 & S2 & S3 & S4 & S5 & T1 & T2 & T3 & T4 & T5 \\
\hline IIR (g) & 100 & 100 & 100 & 100 & 100 & 100 & 98 & 96 & 94 & 92 & 90 & 98 & 96 & 94 & 92 & 90 \\
\hline CIIR (g) & - & - & - & - & - & - & 1.6 & 3.2 & 4.8 & 6.4 & 8 & - & - & - & - & - \\
\hline $\mathrm{GO}(\mathrm{g})$ & - & 0.4 & 0.8 & 1.2 & 1.6 & 2 & 0.4 & 0.8 & 1.2 & 1.6 & 2 & - & - & - & - & - \\
\hline CIIR-GO films & - & - & - & - & - & - & - & - & - & - & - & 2 & 4 & 6 & 8 & 10 \\
\hline Stearic Acid & 2 & 2 & 2 & 2 & 2 & 2 & 2 & 2 & 2 & 2 & 2 & 2 & 2 & 2 & 2 & 2 \\
\hline CBS & 1 & 1 & 1 & 1 & 1 & 1 & 1 & 1 & 1 & 1 & 1 & 1 & 1 & 1 & 1 & 1 \\
\hline Zinc Oxide & 3 & 3 & 3 & 3 & 3 & 3 & 3 & 3 & 3 & 3 & 3 & 3 & 3 & 3 & 3 & 3 \\
\hline TMTD & 1 & 1 & 1 & 1 & 1 & 1 & 1 & 1 & 1 & 1 & 1 & 1 & 1 & 1 & 1 & 1 \\
\hline Sulphur & 1.5 & 1.5 & 1.5 & 1.5 & 1.5 & 1.5 & 1.5 & 1.5 & 1.5 & 1.5 & 1.5 & 1.5 & 1.5 & 1.5 & 1.5 & 1.5 \\
\hline
\end{tabular}

$\mathrm{CN}, \mathrm{D} 1$ to D5, S1 to S5 and T1 to T5 indicates the specimen code for the prepared composites. 


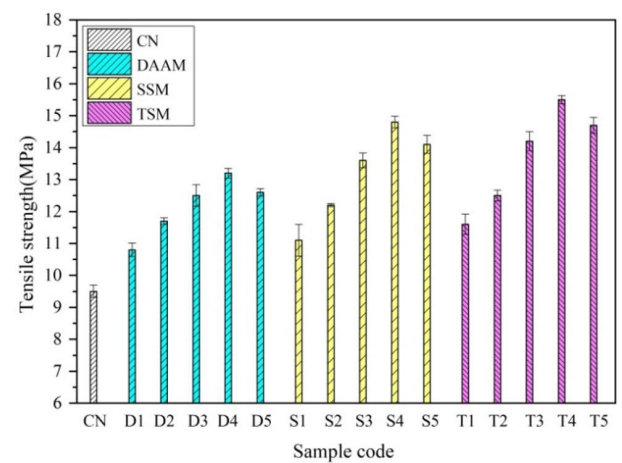

Figure 1. Tensile strength of pure and GO filled uncompatibilized and compatibilied IIR nanocomposites.

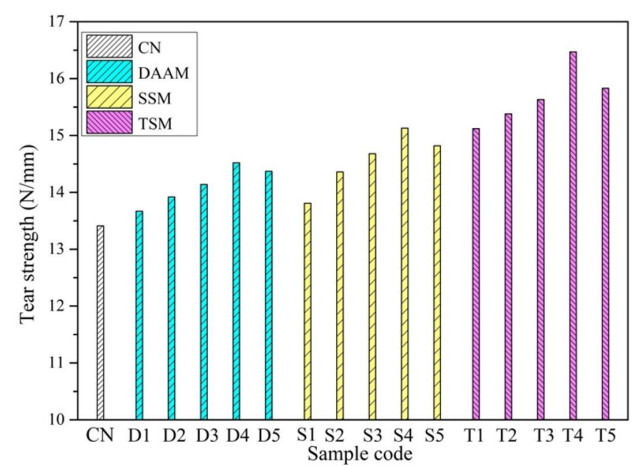

Figure 2. Tear Strength of pure and GO filled uncompatibilized and compatibilied IIR nanocomposites.

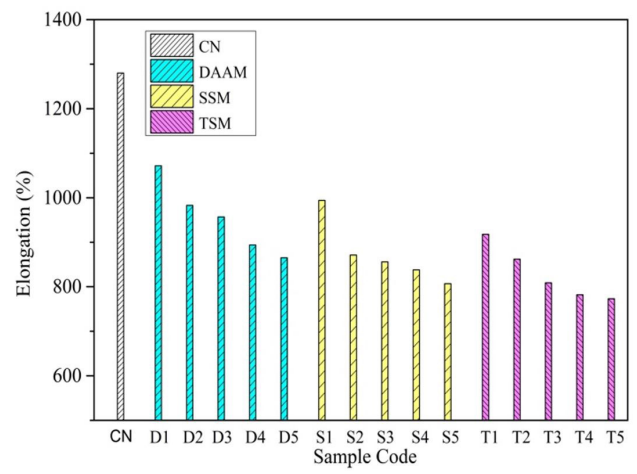

Figure 3. Elongation of pure and GO filled uncompatibilized and compatibilied IIR nanocomposites.

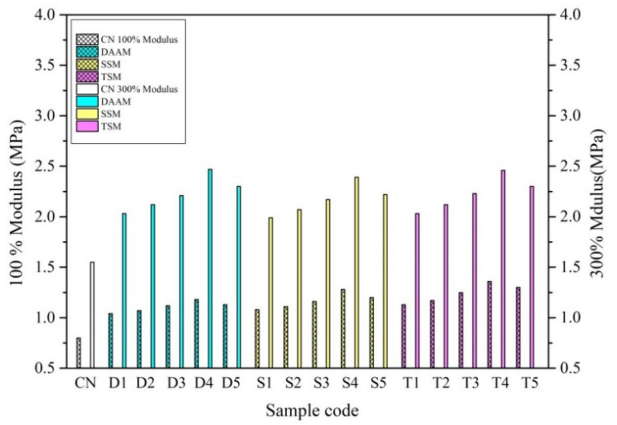

Figure 4. Modulus (100 and 300\%) of pure and GO filled uncompatibilized and compatibilied IIR nanocomposites.
$\% \mathrm{E}$ was reduced up on addition of GO content in IIR matrix. TS, TES and modulus at 100 and $300 \%$ of nanocomposites prepared with SSM (S4) was increased by $56 \%, 7.6 \%, 48 \%$ and $59 \%$ respectively and $\% \mathrm{E}$ was reduced by $37 \%$ when compared with pure IIR.

Similarly, mechanical properties of nanocomposites prepared with TSM (T4) were enhanced by $63 \%, 23 \%, 70 \%$ and $59 \%$ respectively and $\% \mathrm{E}$ was reduced by $40 \%$ when compared to pure IIR. Addition of compatibilier through solution mixing helps in achieving uniform dispersion of GO in IIR matrix. Uniform distribution of GO in IIR matrix leads to form intercalated structure and strong interfacial bonding. So, nanocomposites prepared by TSM shows superior mechanical properties when compared to nanocomposites prepared by other two methods (DAAM and SSM). Mechanical properties starts to deteriorate when reinfocement of GO content increases to $2 \mathrm{wt} . \%$ in IIR matrix (D5, S5 and T5) for the nanocomposites prepared by all three methods. Increment in the GO content above $1.6 \mathrm{wt}$ $\%$ in the developed nanocomposites (all methods) leads to form agglomeration of GO in the matrix which produced the stress concentration on the matrix and decreased the TS, TES, modulus.

\subsection{Gas permeability co-efficient}

Gas barrier properties of the prepared nanocomposites were evaluated by determining the GPC. GPC values of the nanocomposites prepared using all the three methods were depicted in Figure 5.

GPC of nanocomposites prepared with all three methods (DAAM, SSM and TSM) decreases upon addition of GO content in IIR matrix. Nanocomposites prepared with $1.6 \mathrm{wt} . \%$ of GO (D4, S4 and T4) in all three methods shows lower GPC when compared to other samples. GPC of the nanocomposites D4, $\mathrm{S} 4$ and $\mathrm{T} 4 \mathrm{was}$ reduced by $25 \%, 31 \%$ and $36 \%$ respectively when compared to pure IIR. Lower GPC was observed for T4 due to even distribution of GO in IIR matrix. Even distribution of GO in IIR matrix was achieved through TSM which leads to strong interfacial bonding thereby reduces the passage of nitrogen gas. GPC was increased when GO content increases from $1.6 \mathrm{wt} . \%$ to $2 \mathrm{wt} . \%$ (D5, S5 and T5). It is due to agglomeration of GO in IIR matrix which leads to decrease in interfacial bonding between the matrix.

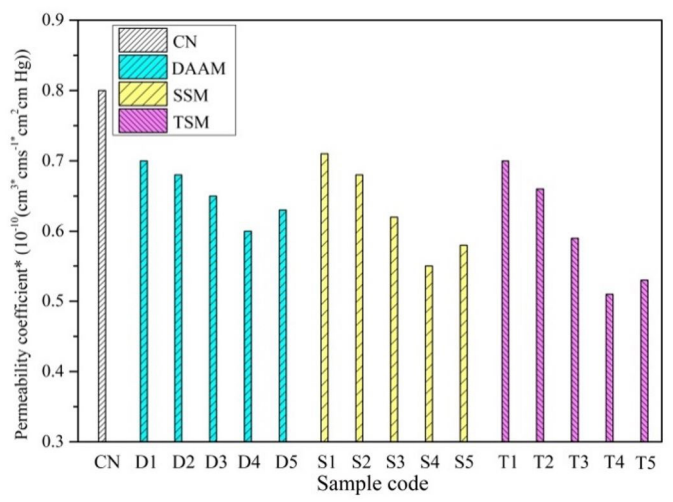

Figure 5. Permeability coefficient of pure and GO filled uncompatibilized and compatibilied IIR nanocomposites. 

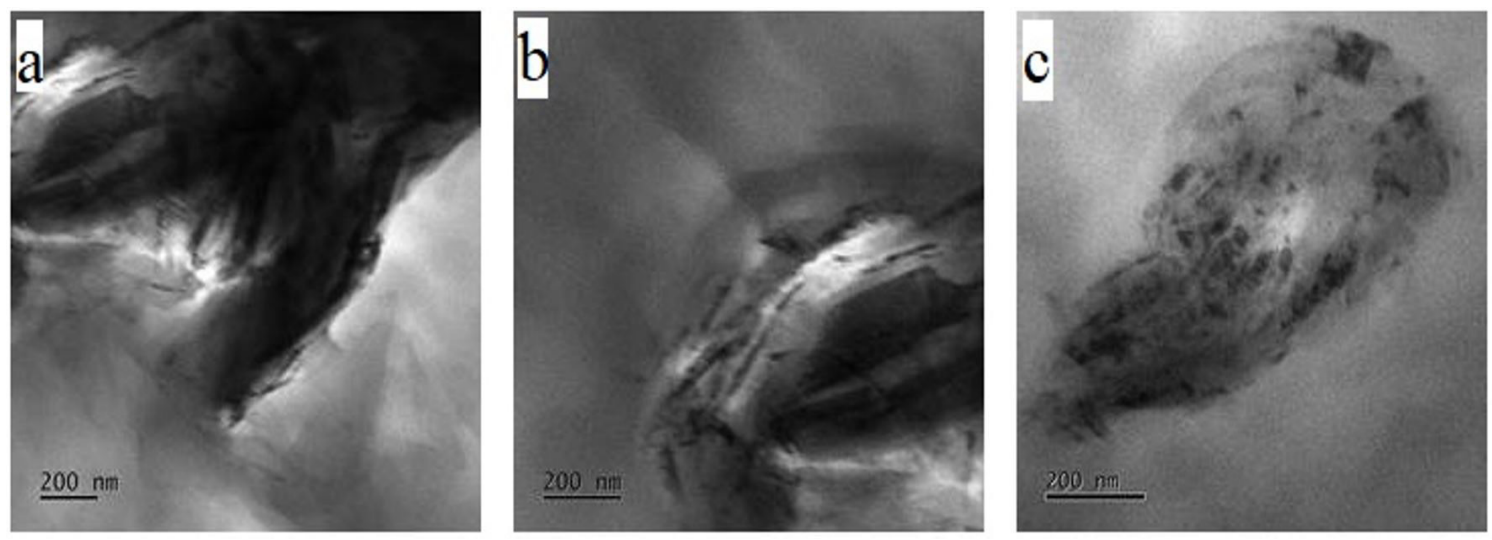

Figure 6. Morphology of nanocomposites at 1.6 wt.\% of GO. (a) DAAM; (b) SSM; and (c) TSM.

\subsection{HR-TEM analysis}

HR-TEM images of developed nanocomposites at 1.6 wt.\% of GO were depicted in Figure 6. In DAAM and SSM, interactions between IIR and GO were weak due to lower interfacial bonding caused discontinuous phase of GO in IIR matrix (Figure 6a, b) which affects the properties of nanocomposites. Even distribution of GO in IIR matrix leads to better interaction and continuous phase during mixing process of TSM (Figure $6 \mathrm{c}$ ) and leads exfoliation of GO in matrix of nanocomposites.

\section{Conclusion}

Graphene oxide nanocomposites was successfully developed in presence and absence of compatibilizer using three different methods (DAAM, SSM and TSM). Morphological studies, mechanical properties and GPC of prepared nanocomposites were examined and properties were compared to identify the suitable method for preparing nanocomposites. Nanocomposites (T4) prepared using TSM with compatibilizer exhibited higher mechanical properties (TS, TES and modulus at 100\% and 300\%) and less GPC when compared to nanocomposite (D4 and S4) prepared with other methods. Enhancement in properties was achieved due to even dispersion of GO in IIR matrix and confirmed thorugh HR-TEM analysis. Increase in weight content of GO in IIR matrix from $1.6 \mathrm{wt} . \%$ to $2 \mathrm{wt} . \%$ leads to aggromeralation which resulted in deterioration of TS, TES and modulus of nanocomposite (D5, S5 and T5) prepared in all three methods. From the above results two step method (TSM) in presence of compatibilizer was found to be a suitable method to develop graphene oxide nanocomposites.

\section{References}

1. Nikje, M. M. A., Moghaddam, S. T., \& Noruzian, M. (2016). Preparation of novel magnetic polyurethane foam nanocomposites by using core-shell nanoparticles. Polímeros: Ciência e Tecnologia, 26(4), 297-303. http://dx.doi.org/10.1590/01041428.2193

2. Arayapranee, W., \& Rempel, G. L. (2008). Morphology and mechanical properties of natural rubber and styrene-grafted natural rubber latex compounds. Journal of Applied Polymer Science, 109(3), 1395-1402. http://dx.doi.org/10.1002/app.28217.

3. Guo, H., Jerrams, S., Xu, Z., Zhou, Y., Jiang, L., Zhang, L., Liu, L., \& Wen, S. (2020). Enhanced fatigue and durability of carbon black/natural rubber composites reinforced with graphene oxide and carbon nanotubes. Engineering Fracture Mechanics, 223, 106764. http://dx.doi.org/10.1016/j.engfracmech.2019.106764.

4. Corrêa, H. L., Sousa, A. M. F., \& Furtado, C. R. G. (2015). Natural rubber latex: determination and interpretation of flow curves. Polimeros: Ciência e Tecnologia, 25(4), 365-370. http:// dx.doi.org/10.1590/0104-1428.1947.

5. Rajasekar, R., \& Das, C. (2011). Development of butyl rubber nanocomposites in presence and absence of compatibiliser. Plastics, Rubber and Composites, 40(8), 407-412. http://dx.doi. org/10.1179/1743289810Y.0000000039.

6. Wu, J., Huang, G., Pan, Q., Zheng, J., Zhu, Y., \& Wang, B. (2007). An investigation on the molecular mobility through the glass transition of chlorinated butyl rubber. Polymer, 48(26), 7653-7659. http://dx.doi.org/10.1016/j.polymer.2007.11.006.

7. Zhu, Y., Zhou, W., Wang, J., Wang, B., Wu, J., \& Huang, G. (2007). Study on damping mechanism based on the free volume for CIIR by PALS. The Journal of Physical Chemistry $B, 111(39), 11388-11392$. http://dx.doi.org/10.1021/jp071670v. PMid:17850129.

8. Silva, V. M., Nunes, R. C. R., \& Sousa, A. M. F. (2017). Epoxidized natural rubber and hydrotalcite compounds: rheological and thermal characterization. Polimeros: Ciência e Tecnologia, 27(3), 208-212. http://dx.doi.org/10.1590/01041428.03416.

9. Malas, A., Das, C. K., Das, A., \& Heinrich, G. (2012). Development of expanded graphite filled natural rubber vulcanizates in presence and absence of carbon black: mechanical, thermal and morphological properties. Materials \& Design, 39, 410417. http://dx.doi.org/10.1016/j.matdes.2012.03.007.

10. Dittrich, B., Wartig, K. A., Hofmann, D., Mülhaupt, R., \& Schartel, B. (2015). The influence of layered, spherical, and tubular carbon nanomaterials' concentration on the flame retardancy of polypropylene. Polymer Composites, 36(7), 1230. http://dx.doi.org/10.1002/pc.23027.

11. Saravanan, N., Rajasekar, R., Mahalakshmi, S., Sathishkumar, T., Sasikumar, K., \& Sahoo, S. (2014). Graphene and modified graphene-based polymer nanocomposites: a review. Journal of Reinforced Plastics and Composites, 33(12), 1158-1170. http://dx.doi.org/10.1177/0731684414524847.

12. Frasca, D., Schulze, D., Wachtendorf, V., Huth, C., \& Schartel, B. (2015). Multifunctional multilayer graphene/elastomer 
nanocomposites. European Polymer Journal, 71, 99-113. http://dx.doi.org/10.1016/j.eurpolymj.2015.07.050.

13. Kang, H., Zuo, K., Wang, Z., Zhang, L., Liu, L., \& Guo, B. (2014). Using a green method to develop graphene oxide/ elastomers nanocomposites with combination of high barrier and mechanical performance. Composites Science and Technology, 92,1-8. http://dx.doi.org/10.1016/j.compscitech.2013.12.004.

14. Young, R. J., Kinloch, I. A., Gong, L., \& Novoselov, K. S. (2012). The mechanics of graphene nanocomposites: a review. Composites Science and Technology, 72(12), 1459-1476. http:// dx.doi.org/10.1016/j.compscitech.2012.05.005.

15. Galimberti, M., Coombs, M., Cipolletti, V., Riccio, P., Riccò, T., Pandini, S., \& Conzatti, L. (2012). Enhancement of mechanical reinforcement due to hybrid filler networking promoted by an organoclay in hydrocarbon-based nanocomposites. Applied Clay Science, 65-66, 57-66. http://dx.doi.org/10.1016/j. clay.2012.04.019.

16. Conzatti, L., Stagnaro, P., Colucci, G., Bongiovanni, R., Priola, A., Lostritto, A., \& Galimberti, M. (2012). The clay mineral modifier as the key to steer the properties of rubber nanocomposites. Applied Clay Science, 61, 14-21. http://dx.doi. org/10.1016/j.clay.2012.03.004.

17. Poikelispää, M., Das, A., Dierkes, W., \& Vuorinen, J. (2013). The effect of partial replacement of carbon black by carbon nanotubes on the properties of natural rubber/butadiene rubber compound. Journal of Applied Polymer Science, 130(5), 3153. http://dx.doi.org/10.1002/app.39543.

18. Frasca, D., Schulze, D., Böhning, M., Krafft, B., \& Schartel, B. (2016). Multilayer graphene chlorine isobutyl isoprene rubber nanocomposites: influence of the multilayer graphene concentration on physical and flame-retardant properties. Rubber Chemistry and Technology, 89(2), 316-334. http:// dx.doi.org/10.5254/rct.15.84838.

19. Kumar, M. K. H., Shankar, S., Rajasekar, R., Kumar, P. S., \& Kumar, P. S. (2017). Partial replacement of carbon black by nanoclay in butyl rubber compounds for tubeless tires. Materials Testing, 59(11-12), 1054-1060. http://dx.doi. org/10.3139/120.111109.

20. Wu, J., Huang, G., Qu, L., \& Zheng, J. (2009). Correlations between dynamic fragility and dynamic mechanical properties of several amorphous polymers. Journal of Non-Crystalline Solids, 355(34-36), 1755-1759. http://dx.doi.org/10.1016/j. jnoncrysol.2009.06.013.

21. Jiang, P., Yang, C., He, X., Rodrigues, A. M., \& Zhang, R. (2017). Viscoelastic changes in chlorinated butyl rubber modified with graphene oxide. Iranian Polymer Journal, 26(11), 861-870. http://dx.doi.org/10.1007/s13726-017-0570-9.
22. Liu, C., Fan, J., \& Chen, Y. (2019). Design of regulable chlorobutyl rubber damping materials with high-damping value for a wide temperature range. Polymer Testing, 79, 106003. http://dx.doi.org/10.1016/j.polymertesting.2019.106003.

23. Wu, J., Xing, W., Huang, G., Li, H., Tang, M., Wu, S., \& Liu, Y. (2013). Vulcanization kinetics of graphene/natural rubber nanocomposites. Polymer, 54(13), 3314-3323. http://dx.doi. org/10.1016/j.polymer.2013.04.044.

24. Potts, J. R., Shankar, O., Murali, S., Du, L., \& Ruoff, R. S. (2013). Latex and two-roll mill processing of thermallyexfoliated graphite oxide/natural rubber nanocomposites. Composites Science and Technology, 74, 166-172. http:// dx.doi.org/10.1016/j.compscitech.2012.11.008.

25. Rajasekar, R., Pal, K., Heinrich, G., Das, A., \& Das, C. (2009). Development of nitrile butadiene rubber-nanoclay composites with epoxidized natural rubber as compatibilizer. Materials \& Design, 30(9), 3839-3845. http://dx.doi.org/10.1016/j. matdes.2009.03.014.

26. Jo, J. O., Saha, P., Kim, N. G., Ho, C. C., \& Kim, J. K. (2015). Development of nanocomposite with epoxidized natural rubber and functionalized multiwalled carbon nanotubes for enhanced thermal conductivity and gas barrier property. Materials \& Design, 83, 777-785. http://dx.doi.org/10.1016/j. matdes.2015.06.045.

27. Li, L., Zhang, J., Jo, J. O., Datta, S., \& Kim, J. K. (2013). Effects of variation of oil and zinc oxide type on the gas barrier and mechanical properties of chlorobutyl rubber/epoxidised natural rubber blends. Materials \& Design, 49, 922-928. http:// dx.doi.org/10.1016/j.matdes.2013.02.057.

28. Azizli, M., Naderi, G., Bakhshandeh, G., Soltani, S., Askari, F., \& Esmizadeh, E. (2014). Improvement in physical and mechanical properties of IIR/CR rubber blend organoclay nanocomposites. Rubber Chemistry and Technology, 87(1), 10-20. http://dx.doi.org/10.5254/rct.13.87951.

29. Rajasekar, R., Nayak, G., Malas, A., \& Das, C. (2012). Development of compatibilized SBR and EPR nanocomposites containing dual filler system. Materials \& Design, 35, 878-885. http://dx.doi.org/10.1016/j.matdes.2011.10.018.

30. Kumar, H. K. M., Subramaniam, S., Rathanasamy, R., Pal, S. K., \& Palaniappan, S. K. (2020). Substantial reduction of carbon black and balancing the technical properties of styrene butadiene rubber compounds using nanoclay. Journal of Rubber Research, 23(2), 79-87. http://dx.doi.org/10.1007/ s42464-020-00039-7.

Received: June 19, 2020

Revised: Sept. 21, 2020

Accepted: Sept. 25, 2020 